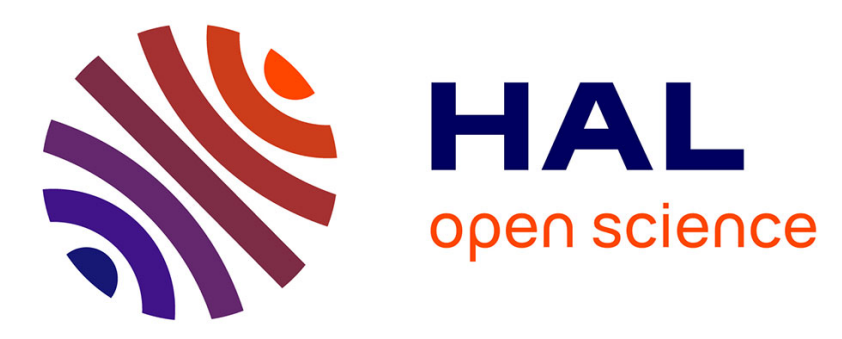

\title{
Assimilation and Modeling of the Atmospheric Hydrological Cycle in the ECMWF Forecasting System
}

Erik Andersson, Peter Bauer, Anton Beljaars, Frederic Chevallier, Elías Hólm, Marta Janisková, Per Kållberg, Graeme Kelly, Philippe Lopez, Anthony Mcnally, et al.

\section{To cite this version:}

Erik Andersson, Peter Bauer, Anton Beljaars, Frederic Chevallier, Elías Hólm, et al.. Assimilation and Modeling of the Atmospheric Hydrological Cycle in the ECMWF Forecasting System. Bulletin of the American Meteorological Society, 2005, 86 (3), pp.387-402. 10.1175/BAMS-86-3-387 . hal-02946358

\section{HAL Id: hal-02946358 https://hal.science/hal-02946358}

Submitted on 3 Nov 2020

HAL is a multi-disciplinary open access archive for the deposit and dissemination of scientific research documents, whether they are published or not. The documents may come from teaching and research institutions in France or abroad, or from public or private research centers.
L'archive ouverte pluridisciplinaire HAL, est destinée au dépôt et à la diffusion de documents scientifiques de niveau recherche, publiés ou non, émanant des établissements d'enseignement et de recherche français ou étrangers, des laboratoires publics ou privés. 


\title{
ASSIMILATION AND MODELING OF THE ATMOSPHERIC HYDROLOGICAL CYCLE IN THE ECMWF FORECASTING SYSTEM
}

by Erik Andersson, Peter Bauer, Anton Beljaars, Frederic Chevallier, Elías Hólm, Marta janisková, Per Kållberg, Graeme Kelly, Philippe Lopez, Anthony McNally, Emmanuel Moreau, Adrian J. Simmons, Jean-Noël Thépaut, and Adrian M. Tompkins

\author{
ECMWF's preparations for cloud and rain assimilation encompass development of \\ linearized physics, improved satellite data utilization, a new humidity analysis, \\ and another look at the "spindown" problem.
}

$\mathrm{E}$ uropean, American, and Japanese satellite agencies have a number of Earth-observation missions with the objective of providing improved measurements of components of the global hydrological cycle-clouds, precipitation, soil moisture, and water vapor-from a range of operational platforms in both polar and geostationary orbits. Significant development of data assimilation methods will be necessary to make full use of both the existing and new types of observations of the water cycle. The small-scale

affiliations: Andersson, Bauer, BeljaArs, Chevallier, Hólm, Janisková, Kållberg, Kelly, Lopez, McNally, Moreau, Simmons, THÉPAUT, AND TOMPKINS - ECMWF, Reading, United Kingdom CORRESPONDING AUTHOR: Dr. E. Andersson, ECMWF, Shinfield Park, Reading, RG2 9AX, United Kingdom

E-mail: erik.andersson@ecmwf.int

DOI:10.1 175/BAMS-86-3-387

In final form 10 September 2004

(C2005 American Meteorological Society variability in atmospheric humidity and its strong dependence on physics and dynamics need to be represented accurately in the assimilation systems. In this paper we report on a comprehensive research program at the ECMWF (see appendix for definitions of all acronyms and abbreviations) devoted to cloud and rain assimilation and humidity analysis. The aim is to explore the information contained in radiances obtained from microwave and infrared sounders and imagers in clear, cloudy, and precipitating skies. Current radiance assimilation methods (McNally et al. 1999, 2000) leave important data gaps in areas of clouds and precipitation, as illustrated in Fig. 1 for the infrared (Fig. 1a) and microwave (Figs. 1b,c). The assimilation is therefore relatively ineffective in correcting for forecast errors in cloudy and rainy regions. To extend direct radiance assimilation to all-sky conditions requires upgrades to the assimilation system itself, and that fast radiative transfer models be extended and enhanced to incorporate the effects of clouds and precipitation. 

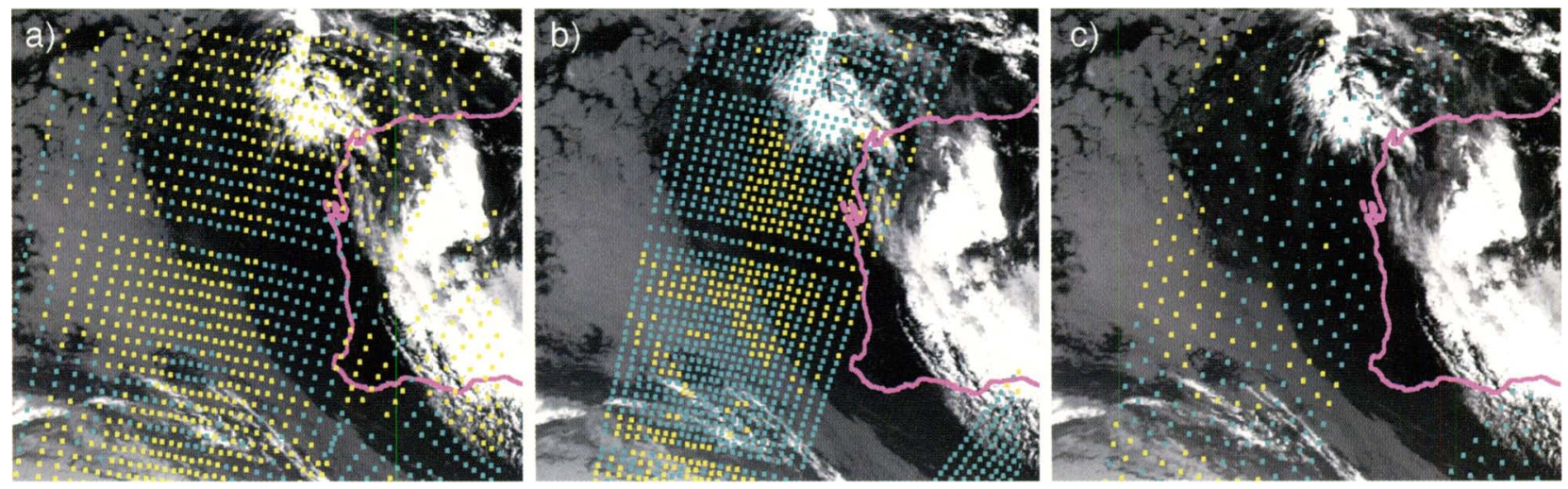

FIG. I. The use of satellite radiance data in current data assimilation systems is restricted by clouds and precipitation. The identification of "clear-sky" depends on the measurements' sensitivity to cloud liquid water. This figure shows data coverage for the used (cyan) and discarded (yellow) data in ECMWF's operational 4DVAR system, for 20030 I 26, plotted on a 2330 UTC GMS cloud image. (a) Infrared tropospheric measurements (HIRS channel-7) are used only in cloud-free areas, leaving large data voids. (b) Microwave temperature-sounding measurements (AMSU-A channel-6) are used in most nonprecipitating areas (provided surface emissivity effects are accurately modeled). (c) Moisture-sounding microwave data (SSM/I channel-7) are used through cirrus but not in areas with thick clouds or precipitation. Current research aims at extending the direct radiance assimilation methods in cloudy and rainy situations.

MODELING ASPECTS AND VALIDATION AGAINST IN SITU DATA. Moist processes are obviously important for the modeling of clouds, precipitation, radiation, and latent heat release. The moisture field depends on parameterized physical processes (Tiedtke et al. 1988; Gregory 1996; Tiedke 1993; Jakob and Klein 1999; Beljaars and Viterbo 1998), which can have substantial uncertainties, but it also depends on the large-scale motion, particularly the vertical motion. One way of assessing the model is by looking at systematic differences between forecasts and analyses. Cross sections of the monthly mean relative humidity difference are shown in Figs. $2 a$ and $2 b$ for day- 1 and day- 5 operational forecasts, respectively. The main difference is in the Tropics, where the model is drier than the analysis. This is associated with a spindown (rapid adjustment to lower values) of precipitation (Fig. 2c) and a spindown of the Hadley circulation, as can be seen from the systematic difference in vertical velocity between forecasts and analysis (Fig. 2d). Because of the additional latent heat release in the Tropics during the first $12 \mathrm{~h}$ of the forecasts (which provides the background for the next analysis), the Hadley circulation is stronger in the analyses than in the forecasts. It is important to note that the differences in relative humidity (Fig. 2a) between forecasts and analyses are up to about $5 \%$, which is fairly small. At this stage it is difficult to say whether the model or the analysis is biased, because most current observing systems do not have an absolute calibration within 5\%. Although the imbalance in moisture between analysis and model is small, the spindown is damaging to the analysis as it maintains an overly active hydrological cycle during the data assimilation. The associated latent heat release and the divergent outflow from the affected regions are likely also overestimated, leading to temperature and wind biases in the tropical analyses.

Boundary layer moisture is an important aspect of the model for two reasons. First, together with surface wind speed, it controls the surface evaporation. Second, boundary layer moisture is the dominant contribution to vertically integrated (total column) water vapor (TCWV). The latter aspect is important in the context of microwave satellite observations, which provide good estimates of TCWV. An example is given in Fig. 3, where the short-range forecast (Fig. 3a) is compared to $1 D^{2} A^{1}{ }^{1}$ retrievals (Fig. 3b; Phalippou 1996) and to a model-independent retrieval (Fig. 3c) (Alishouse et al. 1990). The patterns in the three panels are remarkably similar, suggesting that the observations have a high degree of realism and that the physics and the dynamics of the model do a reasonable job. However, there is again a small systematic difference between the observations and the model. The difference is about $0.5 \mathrm{~kg} \mathrm{~m}^{-2}$ globally averaged, corresponding to about

\footnotetext{
${ }^{1}$ In recent years variational methods have gained popularity in data assimilation applications using satellite radiance data. In IDVAR, independent vertical columns are considered. In 3DVAR, the entire model domain is analyzed at once, and in 4DVAR time sequences of observations and model states are considered.
} 

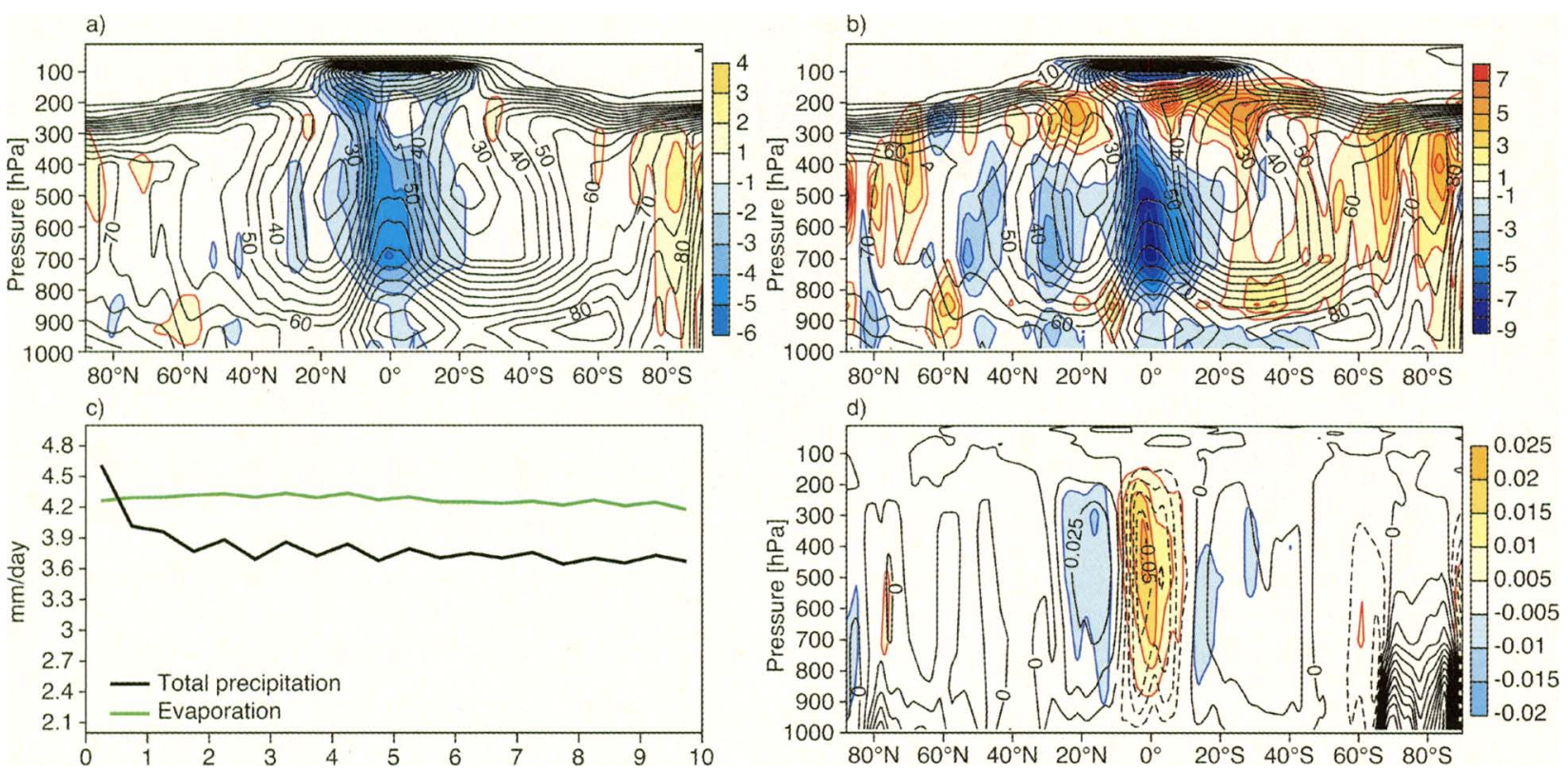

Fig. 2. Color coded, zonal-average monthly mean difference between forecasts and verifying analyses for relative humidity (\%) (a) day I and (b) day 5, Apr 2002, from ECMWF's operational forecasting system (shading interval $\mathrm{I} \%$ ). Blue (yellow) shading indicates that the forecast is less (more) humid than the analysis. The corresponding average relative humidity of the analysis is shown in black contours (contour interval $5 \%$ ). (c) The evolution of precipitation ( $\mathrm{mm} \mathrm{day}{ }^{-1}$, black line) and evaporation ( $\mathrm{mm}$ day ${ }^{-1}$, green) in the tropical band between $30^{\circ} \mathrm{N}$ and $30^{\circ} \mathrm{S}$ during the I0-day forecasts, also averaged over Apr 2002. There is excessive precipitation during the first I $2 \mathrm{~h}$ of the forecasts. Because of the associated latent heat release the Hadley circulation is stronger in the analysis than in the forecasts. (d) The difference in vertical velocity $\left(\mathrm{Pa} \mathrm{s}^{-1}\right)$ corresponding to (a) (shading interval $0.005 \mathrm{~Pa} \mathrm{~s}^{-1}$ ). Blue (yellow) shading indicates that the forecast upward velocity is higher (lower) than the analysis. The averaged analysis is shown in black contours (interval $0.025 \mathrm{~Pa} \mathrm{~s}^{-1}$ ).

$2 \%$ of the global mean $\left(27 \mathrm{~kg} \mathrm{~m}^{-2}\right)$. The discrepancy is small and may be due to model bias or due to biases in the observing or retrieval systems.

The second major factor controlling TCWV is the boundary layer depth. During the EPIC experiment, radiosondes were launched from a ship near $20^{\circ} \mathrm{S}$, $85^{\circ} \mathrm{W}$. A comparison between averaged sonde and model profiles is shown in Fig. 4. The sharp inversion is the result of a subtle balance between large-scale subsiding motion and turbulent entrainment at the top of the cloud layer at the inversion. The model inversion is less sharp than observed and the model boundary layer is slightly lower than observed. This has consequences for TCWV because in this situation, TCWV is to a good approximation equal to the boundary layer depth multiplied by the boundary layer specific humidity. Hence, relative errors in both parameters cause equal relative error in TCWV.

Boundary layer moisture over land is strongly affected by land surface processes through evaporation from the surface (Viterbo and Beljaars 1995; Van den Hurk et al. 2000). Summer precipitation over land is also strongly influenced by land evaporation, which involves a positive feedback: high precipitation leads to more soil moisture, which enhances evaporation feeding back into high precipitation (Beljaars et al. 1996). To control this positive feedback it is necessary to have a good soil moisture data assimilation scheme. Significant work has been done in the past (Viterbo and Courtier 1995; Douville et al. 2000) to optimize the use of SYNOP observations. Currently the EU-funded ELDAS project is underway to further improve the use of SYNOP data and to accommodate other data sources: radiation, precipitation, surface skin temperatures from satellites, and future microwave data (SMOS).

\section{THE TROPICAL HUMIDITY ANALYSIS IN}

ERA-40. The ERA-40 analyses can be viewed as comprising three periods that are characterized in terms of the observations that can influence the humidity analysis. Period A starts in 1957, and has only the conventional in situ surface and radiosonde measurements available. Period B, from 1973, uses the in situ measurements and infrared radiances, but not SSM/I data. The infrared data are from VTPR instruments from 1973 to 1978 and from HIRS instruments beyond 1978. In period C, from 1987 onward, in situ measurements, HIRS infrared radiances, and IDVAR retrievals of 
a) First guess

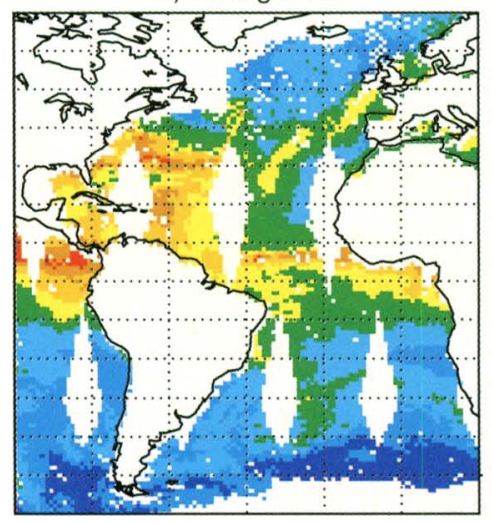

b) SSM/I 1D-Var

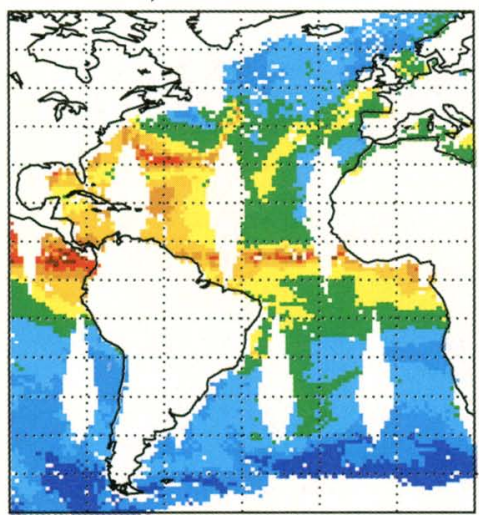

c) SSM/I Regression

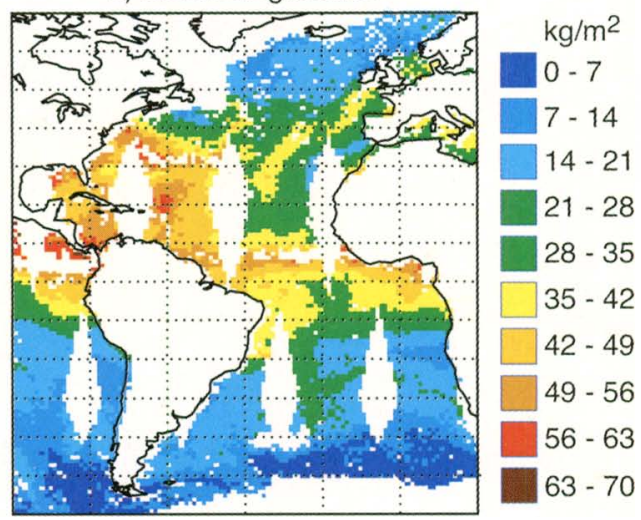

FIG. 3. Total-column water vapor ( $\mathrm{kg} \mathrm{m}^{-2}$, see legend) for the (a) model background (a short forecast), (b) a IDVAR retrieval, (c) and a model-independent retrieval algorithm for 29 Jul 2002, using data from the SSM/I instrument. The three estimates of atmospheric humidity show good correspondence. Biases are within $2 \%$ globally.

TCWV from SSM/I radiances are all assimilated. Diagnosis of hydrological aspects of the ERA-40 products has been carried out. These studies have shown some pronounced differences in the behavior of the three periods that are almost certainly related mainly to the changes in data used rather than to natural earthsystem changes.

Information on the precipitation and evaporation averaged over land and sea, for each of the three periods, is shown in Table 1, based on values provided by the Max Planck Institute for Meteorology, Hamburg, a partner in the ERA-40 project. ERA-40 results (based on 6-h forecasts) are compared with those from ERA15 for period $C$, with those from the NCEP reanalysis for periods $\mathrm{A}$ and $\mathrm{B}$ and other relevant datasets (see caption). The period C ERA-40 precipitation for the years 1989-95 is substantially larger than that given by any of the verifying datasets, and substantially larger than the ERA15 precipitation for the years 1989 93. Precipitation exceeds evaporation over sea as well as land. Period $\mathrm{B}$ precipitation is also relatively high, though not as high as in period C. Again, precipitation exceeds evaporation over sea as well as land. Only in period A (when no satellite data were available for assimilation) is the oceanic precipitation, averaged globally, of the order of that given in the observational datasets for the various periods, and less than the oceanic evaporation.

The hydrological balance of the ERA-40 data assimilation cycles in- cludes a component with no physical counterpart: the systematic addition or removal of atmospheric moisture by the humidity analysis. The lack of physical balance in the hydrological cycle represented by the ERA40 products for the latter two periods of the reanalysis is due to the assimilation system's use of satellite data to correct what is perceived to be a too-dry background model state over the tropical oceans. The assimilating model rejects almost all of the moisture added by the analysis. The resulting excessive tropical oceanic precipitation is arguably the most serious problem diagnosed in ERA-40.

Maps of analysis increments from ERA-40, and additional observing-system experiments, confirm that the period $\mathrm{C}$ analyses are generally moistened over tropical oceans by the assimilation of HIRS and SSM/I data. Figure 5 presents time series of tropical means of
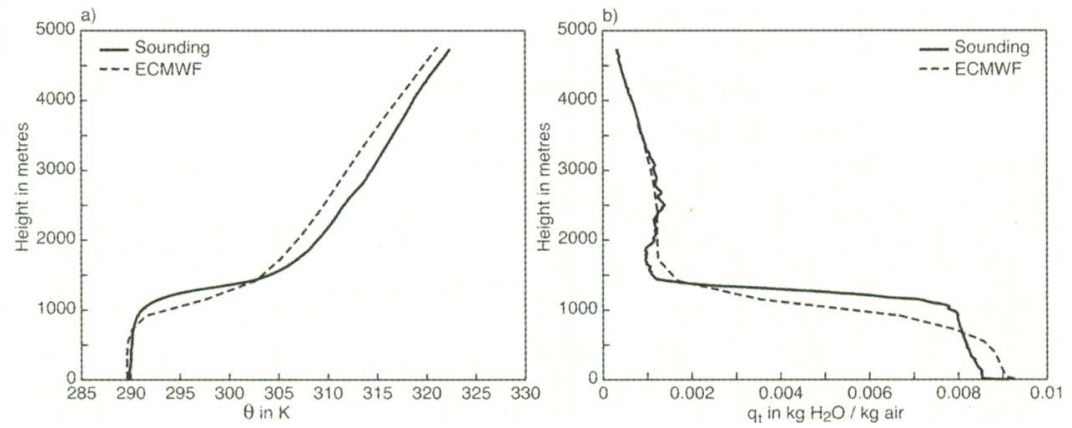

FIG. 4. Satellite instruments (e.g., SSM/I) provide good measurements of the total-column water vapor over ocean. In the subtropical subsidence regions, errors in modeled TCWV can be dominated by errors in the boundary layer height. Shown are 6-day averages of radiosonde observations (full lines) and corresponding averages of ECMWF model profiles (dashed) of (a) potential temperature and (b) specific humidity at the "IMET-Stratus location," $20^{\circ} \mathrm{S}, 85^{\circ} \mathrm{W}$. The figure was kindly provided by Chris Bretherton, University of Washington. 
the TCWV increment, the precipitation from 6-h background forecasts, and the TCWV itself for the entire ERA-40 period from 1957 to 2002. A substantial jump in the precipitation rate can be seen over the second half of 1991. After a slight decline, the rate rises sharply again toward the end of 1994, with high rates (averaging around $5.5 \mathrm{~mm} \mathrm{day}^{-1}$ ) maintained throughout 1995-2002. This temporal variation in precipitation rate closely follows the temporal variation in the TCWV increment. The results from January 1958 to June 1965 show only weak drying increments from the assimilation of in situ tropical data. Precipitation rates are in the range of 3.6-4.0 $\mathrm{mm}$ day $^{-1}$. The increments since 1991 amount to about $1 \%$ of the TCWV, added to the analysis every $6 \mathrm{~h}$. Most of the added moisture is rained out, as it must be for the TCWV to keep reasonable values. The TCWV is nevertheless, on average, around $10 \%$ higher in period $\mathrm{C}$ than in period $\mathrm{A}$, generally increasing and reaching particularly high values during the strong 1998 El Niño event. The substantial increase in ERA-40 rain rates in the second half of 1991 was due in part to misinterpreted effects of volcanic aerosols on HIRS infrared radiances following the eruption of Mt. Pinatubo.

Various deficiencies of the assimilation system have been suggested as causes of the large tropical rain rates seen in the short-range ERA-40 and operational forecasts. Problems with the bias correction of the satellite radiances, the vertical structure of the increments produced by the analysis scheme, and the model representation of tropical moist processes are all possible candidates, and some sensitivity has been seen to changes in these areas. If tropical circulations in assimilation cycles are too intense, there will be a tendency for descent regions to be too dry. It is in just these cloud-free regions that the satellite humidity data tend to be used, and the observations act to moisten what they see to be an overly dry atmosphere. The moisture added in the descent regions may then be fed into the precipitating ascent regions, where it can fuel the maintenance of the too-strong circulations. If this is indeed a significant factor, then assimilation of rainaffected microwave radiances (next section) would offer a better control of the tropical circulation.

\section{SATELLITE REMOTE SENSING OF HUMID-}

ITY. In recent years, several NWP centers have shown the benefit of assimilating water vapor information from satellites in operational forecasting systems. Due to the scarcity of conventional upper-air data to constrain the model humidity fields over the oceans, satellite data indeed offer a valuable source of information that is being exploited. It has been shown that
TABLE I. Global precipitation and evaporation over land and ocean for the years 1958-61, 1973-75, and $1989-95$ in $10^{15} \mathrm{~kg} \mathrm{yr}^{-1}$ from the reanalyses performed at NCEP and ECMWF (ERA-15 and ERA40) and from other data sources: GPCC (Rudolf et al. 1996), GPCP (Huffman et al. 1997), CMAP (Xie and Arkin 1997), and CRU (New et al. 2000). For the two earlier periods of ERA-40 only CRU data over land excluding Antarctica are available as observations. Also shown are climatological estimates (Baumgartner and Reichel 1975, hereafter BR). The ERA-I5 results are for 1989-93 only.

\begin{tabular}{|lcccc|}
\hline $\begin{array}{l}\text { Period A } \\
\text { (1958-61) }\end{array}$ & Land & \multicolumn{3}{c|}{ Ocean } \\
\hline Precip & Evap & Precip & Evap \\
\hline NCEP & 92 & 71 & 401 & 472 \\
\hline CRU & 117 & 96 & 409 & 453 \\
\hline BR & 103 & - & - & - \\
\hline Period B & Land & & Ocean & \\
(1973-75) & Precip & Evap & Precip & Evap \\
\hline ERA-40 & 123 & 72 & 454 & 446 \\
\hline NCEP & 117 & 94 & 384 & 429 \\
\hline CRU & 103 & - & - & - \\
\hline BR & 111 & 71 & 385 & 424 \\
\hline Period C & Land & & Ocean & \\
(I989-95) & Precip & Evap & Precip & Evap \\
\hline ERA-40 & 116 & 76 & 476 & 448 \\
\hline ERA-15 & 114 & 83 & 390 & 434 \\
\hline GPCC & 97 & - & - & - \\
\hline GPCP & 106 & - & 376 & - \\
\hline CMAP & 98 & - & 394 & - \\
\hline BR & 111 & 71 & 385 & 424 \\
\hline
\end{tabular}

assimilated humidity information reduces analysis biases and produces a large impact that can be retained in the forecast for several days, in experiments with HIRS (McNally and Vesperini 1996), SSM/I (Gérard and Saunders 1999), and METEOSAT (Munro et al. 2004; Köpken et al. 2004) radiances. It should be mentioned that the development of variational methods facilitated the transition from using retrievals to direct radiance assimilation in 3DVAR (Andersson et al. 1994, 1998; Derber and Wu 1998; McNally et al. 1999, 2000; English et al. 2000) and 4DVAR (Rabier et al. 2000), allowing a continuous improvement in the assimilation of information from satellite instruments (Simmons and Hollingsworth 2002). Currently, a wide range of operational satellite systems provides humidity information. Table 2 lists the data available at ECMWF for monitoring or assimilation, and shows data counts and the main characteristics of each instrument. The main shortcoming of the instruments 

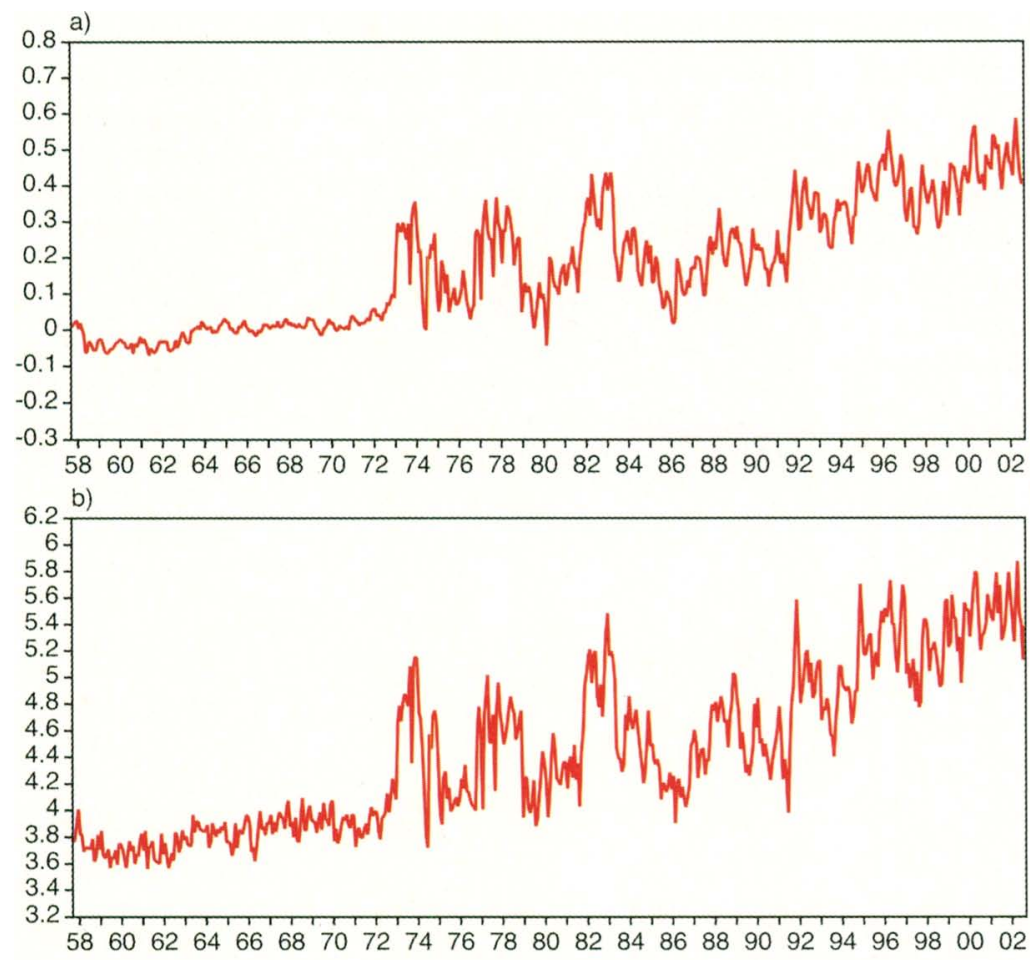

c)

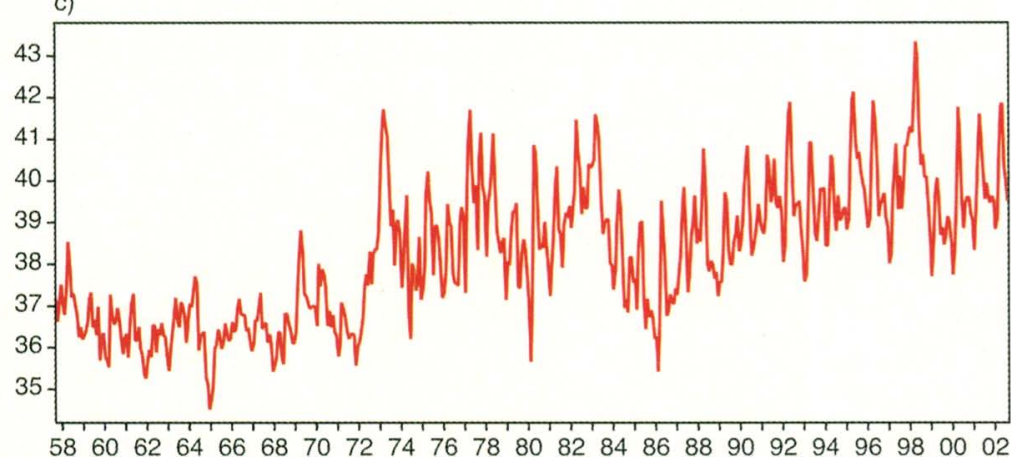

FIG. 5. The moisture analysis and variations in the availability of humidity data can have a strong influence on the analyzed precipitation in the Tropics. The figure shows time series of tropical-mean increments in (a) total-column water vapor $\left(\mathrm{kg} \mathrm{m}^{-2}\right)$, (b) precipitation rate in 6-h forecasts $\left(\mathrm{mm} \mathrm{day}^{-1}\right)$, and (c) analyzed TCWV $\left(\mathrm{kg} \mathrm{m}^{-2}\right)$, averaged over all analysis cycles for each month from 1958 to 2002 of ECMWF's reanalysis (ERA-40). The tropical precipitation correlates strongly with the mean TCWV increments, which vary over the period due to variations in the availability of satellite humidity data.

has been their poor vertical resolution, which makes the distribution of humidity information in the vertical a delicate problem.

Another important aspect of the assimilation of humidity-sensitive radiances concerns the quality of the RT model calculating radiances from the NWP model variables. Direct assimilation of radiances (rather than retrievals) is preferred because it ensures consistency between different satellite observations and because the description of observation errors is easier in terms of radiances. However, great care has to be taken to properly handle systematic errors in the observations and in the RT model through bias correction procedures (Harris and Kelly 2001). In Europe, the development of RT codes for NWP is coordinated within EUMETSAT's NWP-Satellite Application Facility. Recently an improved version of the RTTOV (Saunders et al. 1999) fast regressionbased RT model has been developed (Saunders et al. 2002; Matricardi et al. 2004). The new version addresses significant deficiencies highlighted by Garand et al. (2001) in intercomparisons with accurate line-by-line computations. This new version is also an essential step toward accurate assimilation of radiances from the water vapor channels of MSG, AIRS, and IASI (Matricardi and Saunders 1999; Matricardi 2003). For SSM/I it is important that RTTOV now includes the fast sea surface emissivity model FASTEM-2 (English and Hewison 1998), and it thus supersedes the older RTSSMI (Phalipou 1993). In Fig. 6 we compare the distributions of background, bias-corrected background, and analysis departures from RTSSMI (top) and RTTOV (lower panels) for a 5-day period in May 2002. For all seven SSM/I channels (only the $37-\mathrm{GHz}$ channels are shown) the background departures and the biases are significantly smaller when RTTOV is used. This improvement is a result of the better parameterization of seawater permittivity as well as the inclusion of nonspecular reflection contributions with increasing surface roughness (Ellison et al. 2003).

The SSM/I instrument measures horizontally and vertically polarized radiance at three frequencies (19, 37 , and $85 \mathrm{GHz}$ ) and vertically polarized radiances at $22 \mathrm{GHz}$. These channels show a differential sensitivity to the integrated atmospheric water vapor content and wind-induced sea surface roughness. This information was assimilated through 1DVAR retrievals of TCWV and wind speed (Phalipou 1996). The largest analysis changes caused by the assimilation of this information occurred in the Tropics and in the Southern Hemi- 
sphere. Here, the data caused a significant moistening of the analysis, which is difficult to verify due to the absence of an extensive conventional observing system measuring TCWV. However, earlier studies (McNally and Vesperini 1996) have shown a good agreement between TCWV from SSM/I and the humidity information from other satellite instruments such as HIRS. The use of SSM/I 1DVAR retrievals has recently been replaced by direct assimilation of SSM/I radiances in the 4DVAR system (Bauer et al. 2002), restricted to clear-sky and thin cloud conditions. Singlecycle experiments showed that the TCWV increments are fairly comparable between 1DVAR and direct radiance assimilation. Longer cycling experiments confirmed these results. The hydrological budget remained almost unchanged, as did the spindown of precipitation rate.

Recognizing the importance of global humidity information, space agencies have invested in a number of new and planned satellite missions that will further enhance the capability to observe the highly variable distribution of humidity in the atmosphere: AIRS onboard Aqua (launched in June 2002) and IASI onboard METOP (expected in 2005) provide a substantial increase of water vapor information compared with the traditional infrared radiometers. A first conservative AIRS assimilation strategy, restricted to cloud-free conditions (McNally and Watts 2003), was imple- mented at ECMWF in October 2003 (Table 2). Future investigations will be directed toward exploring more of the rich information in data from this class of highspectral-resolution instruments in the presence of clouds (Chevallier et al. 2004). The SEVIRI instrument onboard MSG has 4 times as many channels as the current METEOSAT instruments. Extra window channels should improve the cloud detection and the quality of the MSG clear-sky radiance product. The availability of two water vapor channels $(7.3$ and $6.2 \mu \mathrm{m})$ modestly increases the vertical resolution. The first satellite in this new series (MSG-1) was launched in August 2002, and data are beginning to become available for analysis. The SSMI/S on board DMSP-16 (launched October 2003) combines AMSU-A, AMSU-B, and $\mathrm{SSM} / \mathrm{I}$ sensing capabilities in a single instrument. The combined availability of imaging and sounding channels will improve the vertical resolution with respect to water vapor structures. Passive limb sounders (such as MIPAS on board ENVISAT) and active GPS radiooccultation measurements (e.g., GRAS, COSMIC) can provide high vertical resolution measurements of water vapor. These new and planned missions are very promising, but also challenging, since they raise potentially difficult assimilation problems in the horizontal.

CLOUD AND RAIN ASSIMILATION. Operational NWP centers have a growing interest in assimi-

\begin{tabular}{|c|c|c|c|c|c|}
\hline Instrument & Spacecraft & $\begin{array}{c}\text { Total } \\
\text { number } \\
\text { processed }\end{array}$ & $\begin{array}{l}\text { No. } \\
\text { of used } \\
\text { data }\end{array}$ & $\begin{array}{l}\text { No. of channels, } \\
\text { available and } \\
\text { (used) }\end{array}$ & $\begin{array}{l}\text { Humidity } \\
\text { sensitivity of } \\
\text { used data }\end{array}$ \\
\hline Imager, & METEOSAT-5 & 181,000 & 20,000 & $2(1)$ & Upper \\
\hline geostationary & METEOSAT-7 & 312,000 & 43,000 & Infrared & troposphere \\
\hline \multirow[t]{3}{*}{ orbit } & GOES- 9 & 899,000 & 37,000 & & \\
\hline & GOES- 10 & 553,000 & 26,000 & & \\
\hline & GOES- 12 & 496,000 & 17,000 & & \\
\hline HIRS, & NOAA- 14 & 64,000 & 0 & $19(6)$ & Mostly upper \\
\hline \multirow[t]{3}{*}{ polar orbiting } & NOAA- 15 & 63,000 & 0 & Infrared & troposphere \\
\hline & NOAA-16 & $1,684,000$ & 88,000 & & \\
\hline & NOAA-I 7 & $1,423,000$ & 77,000 & & \\
\hline AMSU-B, & NOAA- 15 & 402,000 & 0 & $5(3)$ & Upper and mid- \\
\hline \multirow[t]{2}{*}{ polar orbiting } & NOAA-16 & 399,000 & 34,000 & Microwave & troposphere \\
\hline & NOAA- 17 & 403,000 & 33,000 & & \\
\hline SSMI, & DMSP-13 & 88,000 & 38,000 & $7(7)$ & Total column \\
\hline \multirow[t]{2}{*}{ polar orbiting } & DMSP-I 4 & 89,000 & 33,000 & Microwave & \\
\hline & DMSP-I5 & 88,000 & 39,000 & & \\
\hline AIRS, & Aqua & $52,242,000$ & $1,915,000$ & $2378(230)$ & Upper and mid- \\
\hline polar orbiting & (EOS-PM) & & & Infrared & troposphere \\
\hline
\end{tabular}




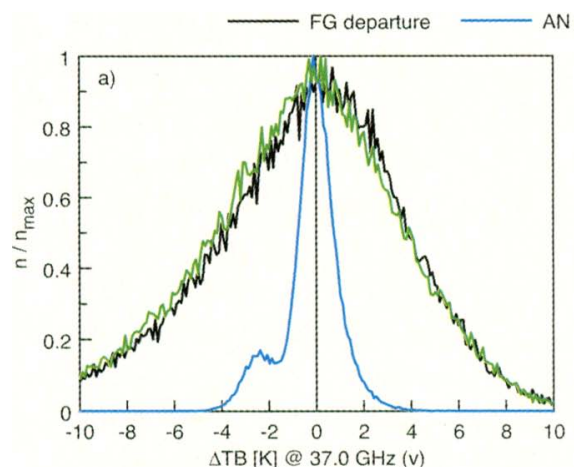

AN departure

FG departure (bias)
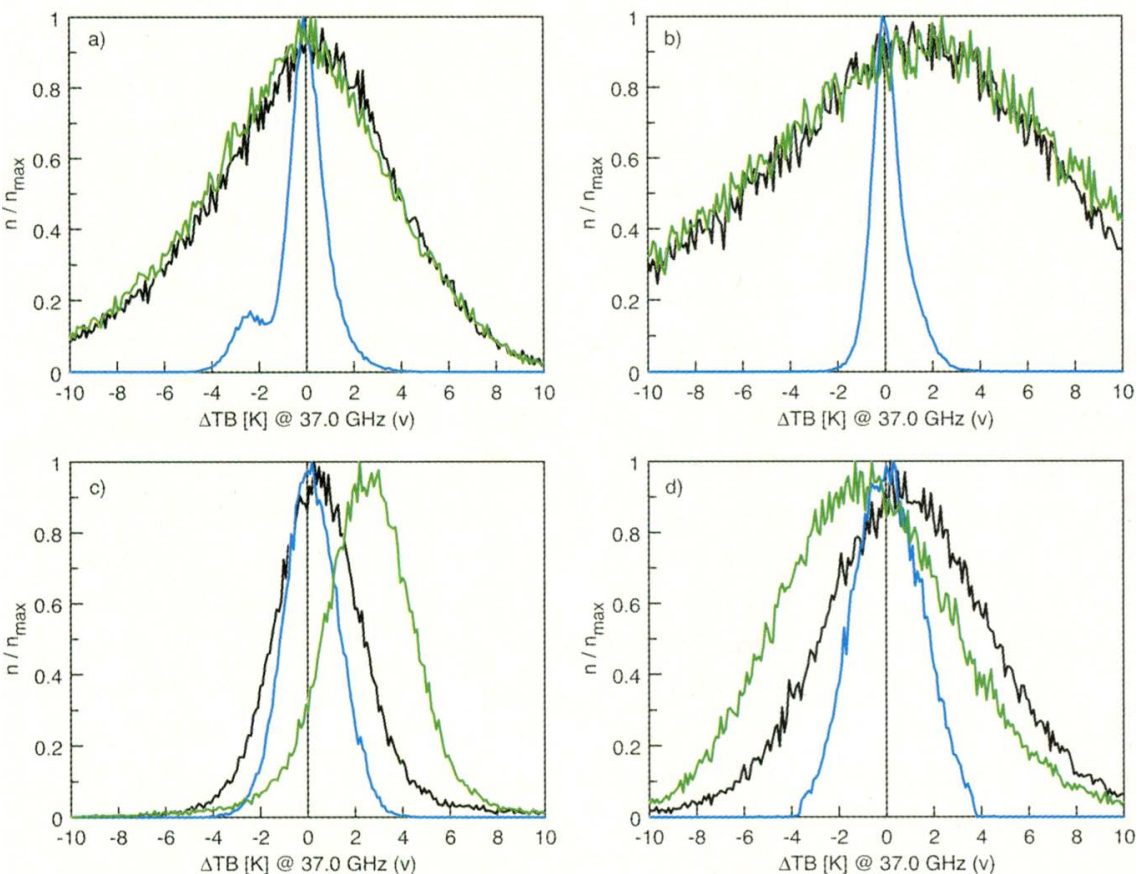

FIG. 6. Accurate radiative-transfer models are required to simulate the satellitemeasured radiances from temperature, humidity, and other quantities provided by the forecast model. Differences between observed and simulated radiances are extensively monitored. Recent improvements in the accuracy of RT modeling [comparing RTSSMI (old) against RTTOV (new)] is illustrated for the $37-\mathrm{GHz}$ SSM/I channels in vertical (V) and horizontal $(H)$ polarization: (a) V, old RT; (b) H, old RT; (c) V, new RT; and (d) H, new RT model. The three curves show observation minus short-range forecast without (green) and with (black), bias-correction, and observation minus analysis departures (blue).

lating satellite observations in cloudy and rainy regions (Treadon 1997; Tsuyuki 1997; Macpherson 2001; Marécal and Mahfouf 2002). Measurements in cloudy regions contain valuable information on temperature, humidity, and wind that is fundamentally different from clear-sky areas. Regions where forecast error is most sensitive to initial-condition error are often cloudy (McNally 2002). Current satellites already provide some cloud-related information that is not generally assimilated in operational analyses. Variational assimilation schemes can, in principle, handle cloud and precipitation observations. However, these data represent features and processes that are more discontinuous and have smaller spatial and temporal scales than most currently used data. Several aspects of the data assimilation systems will need to be revised, as increased accuracy and efficiency may be required.

Marécal and Mahfouf (2002) have compared the performance of two different methods for assimilating surface rainfall observations in the ECMWF 4DVAR system. In the first approach, a 1DVAR technique (Marécal and Mahfouf 2000) was used to generate increments of
TCWV, which led to simulated surface rain rates that better matched the observations. The resulting $1 \mathrm{DVAR}$ TCWV retrievals were then assimilated in 4DVAR. This method is referred to as "1DVAR + 4DVAR" (Marécal and Mahfouf 2003). The second approach is direct assimilation of surface rain rate observations in the 4DVAR system, and is referred to as "Direct 4DVAR" assimilation of rain rates. The observations in the above studies were rain-rate retrievals from satellite microwave measurements from TMI and SSM/I (Bauer et al. 2001).

Global 1-month assimilation experiments using both the above methods have been conducted at full resolution (T511 forecast model with analysis increments at T159). The results (Marécal et al. 2001, 2002) show that the ECMWF model can have opposite humidity biases in rainy and nonrainy areas, by about $5 \%-10 \%$ in TCWV (with opposite signs in the midlatitudes and Tropics). When satellite data are used only in nonrainy conditions, extrapolation of information into the rainy areas often degrades the analysis there by increasing the bias further. This provides a strong motivation to extend the use of satellite humidity data to all-sky conditions. Another important result is that the strong nonlinearities in the observation operators for rain rates-that is, the moist convection scheme-led to convergence problems in the 4DVAR solution algorithm. The 1DVAR + 4DVAR method partly avoids this problem by treating those nonlinearities outside of 4 DVAR. In many respects the most attractive assimilation approach would be direct radiance assimilation of cloud- and rain-affected microwave radiances. However, this requires substantial development of 1) linearized versions of cloud and convection schemes, 2) accurate RT models for cloudy and precipitating skies, and 3) further developments of the 4DVAR system. This is currently our main development strategy, as outlined in the following sections. 
Revised convection and cloud schemes. A modified version of ECMWF's operational convection scheme has been developed for an improved variational assimilation of cloud and precipitation observations. While the scheme shares the fundamental features of the original mass-flux scheme (Tiedtke 1993), it behaves more linearly with respect to changes in the key parameters. All types of convection (shallow, midlevel, and deep) are treated similarly. In particular, the link between the model control variables and the subgridscale convective quantities is expressed through a single formulation that depends on the relaxation of CAPE in time. The initial characteristics of the updrafts are now determined from surface heat fluxes. The total entrainment is a function of the height above cloud base, while the detrainment rate is set equal to the entrainment rate, except close to cloud top where a constant detrainment is applied. Simplified calculations of downdrafts and convective momentum transport are also included in the modified parameterization.

The new convection scheme has first been validated in the single-column version of the ECMWF model and then in the full 3D model for periods of up to 4 months. In the context of such standard forecasts, the new parameterization behaves similarly to the more sophisticated operational scheme. It has been verified that the domain of validity of the linear assumption (Fillion and Mahfouf 2003) now extends to larger perturbations - to perturbations of the size of typical analysis increments.

For the purpose of rain and cloud assimilation, a new statistical diagnostic cloud scheme has been developed (Tompkins and Janisková 2004). The new scheme includes a parameterization of large-scale precipitation formation based on Sundquist et al. (1989) and a new parameterization of precipitation evaporation based on the subgrid-scale variability of total wa-

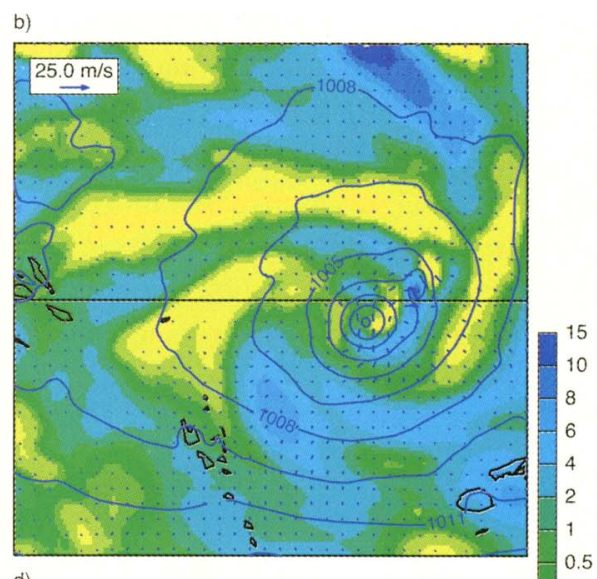

d)

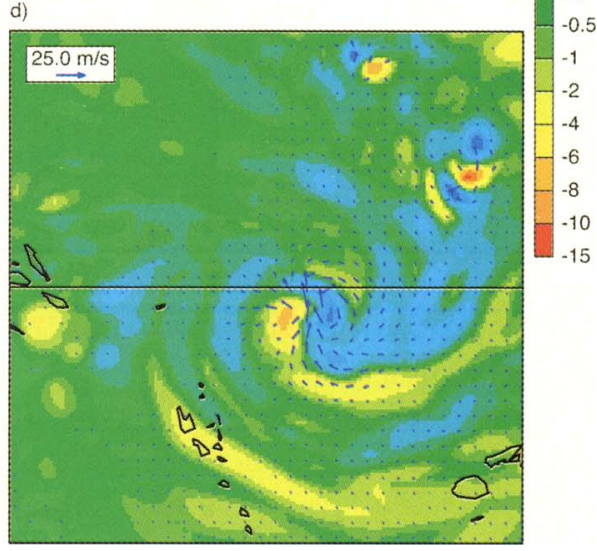

Assimilation of rain-affected microwave radiances. The assimilation of rain-affected microwave radiances requires the development of a fast RT model (Bauer 2002; Moreau et al. 2002) that accounts for scattering effects due to raindrops and ice particles. Similarly, a tool to compute cloud-affected infrared radiances has been developed. Both models have been used to evaluate the ECMWF moist physics (Chevallier et al. 2001; Chevallier and Kelly 2002; Chevallier and Bauer 2003). The 1DVAR assimilation of rain-affected radiances has been compared with assimilation of rain rates for the case of Supertyphoon Mitag in March 2002 (using TMI data) and for a midlatitude front in January 2002 (us- 
ing SSM/I). Both IDVAR methods succeeded in producing reasonable and coherent temperature and specific humidity increments that correct the simulated radiances toward the satellite observations (Moreau et al. 2004) or improve the model's surface rain rates. The computational cost is less for rain-rate assimilation as the RT calculations are not required in that case. However, the following issues have to be considered:

1) with rain-rate assimilation, precipitation cannot be activated where the background rain rate is zero as there is then no sensitivity of rain rate with respect to humidity;

2) rain-rate assimilation is dependent on the performance of the selected rain-rate retrieval algorithm that may be based on assumptions that are not consistent with the NWP model physics;

3) the combined sensitivity of radiances to water vapor, cloud water, ice and precipitation allows a more general application and avoids aliasing; and

4) assimilating radiances permits a more flexible selection of microwave channels available from a given instrument, thus making the transfer of the method between different instruments relatively straightforward.

Figures $7 \mathrm{a}$ and $7 \mathrm{~b}$ show an example of the analysis increments of TCWV, lower-level $(850 \mathrm{hPa})$ wind vectors, and surface pressure from a single 4DVAR analysis using the above-described TCWV retrievals from rain-rate and radiance observations, respectively. The case is Tropical Cyclone Zoe on 1200 UTC 26 December 2002. The panels present the analyses assimilating rain rates (Fig. 7, left panels) and radiances (Fig. 7, right panels) using TMI observations. The TMI data are the only observations that are assimilated over the main part of the storm. The main signal is a northeastward displacement of the cyclone as well as an intensification of the central low pressure by $5-10 \mathrm{hPa}$. The radiance assimilation produces larger increments with a stronger moistening in the eastern part of the cyclone as well as larger wind increments, despite the somewhat lower data coverage (not shown here). The main reason for this is the better differential sensitivity of radiances to cloud and rainwater that is still effective in heavy precipitation due to the usage of the $10.7-\mathrm{GHz}$ TMI channels. The fact that the assimilation of precipitation observations displaces the model clouds and rain (apart from modifying the system's intensity) ensures that this information is carried into the forecast for a period of time. Figures $7 \mathrm{c}$ and $7 \mathrm{~d}$ illustrate this effect for the 24-h forecast. They show the difference between the rain assimilation and a control experiment in the 24-h forecasts of TCWV and the 850-hPa wind vector. The initial displacement of the system generates "dipoles" of positive-negative TCWV differences due to the TCWV gradient between the inside and the outside of the storm. The forecast differences are similar in magnitude to the analysis increments. It can thus be expected that the assimilation of rain information will have a substantial impact on both analyses and forecasts.

The above-described strategies for the assimilation of rain-affected microwave radiances can be extended to the assimilation of cloud information from infrared observations, provided a suitable radiation model is available. Preliminary 1DVAR studies have been based on observations from HIRS (Chevallier et al. 2002) and on broadband long wave fluxes from the ARM field campaign (Janisková et al. 2002b). It has been shown that the 1DVAR retrieval is capable of generating and removing clouds as necessary.

Required improvements of the 4DVAR system. Regarding the assimilation system itself, an important requirement is a better consistency between the linear (low resolution) and nonlinear (full resolution) models used in 4DVAR (Courtier et al. 1994) in terms of resolution, moist physics, and time integration scheme for humidity. In a revised 4DVAR-solution algorithm implemented in January 2003, the low-resolution linearization trajectory is created through interpolation of the high-resolution fields (Trémolet 2004). This ensures that model profiles are similar at high and low resolution, and that physical processes (i.e., those associated with cloud and rain) are active at similar locations at both resolutions. The revision will also allow further increases in analysis resolution (to T255 and beyond), when appropriate, depending on the availability of accurate linear physics (Mahfouf 1999; Janisková et al. 2002a) and on the availability of highresolution observations. The inclusion of physical processes as observation operators will increase the nonlinearity of the assimilation problem (Chevallier et al. 2004) and more frequent relinearization may be necessary.

\section{A NEW FORMULATION OF THE HUMIDITY}

ANALYSIS. At the present level of analysis accuracy, the background errors for all analysis variables except humidity appear to have near-normal distributions, which can be approximated by Gaussian PDFs. The use of Gaussian PDFs in a variational analysis results in a quadratic cost function, which can be minimized the most efficiently. Detailed studies have shown that humidity has the least Gaussian and the least homoge- 
neous background errors of all the analysis variables. This is due to the condensation effects near saturation and the strict limit at zero humidity. It is suspected that this unaccounted non-Gaussian behavior is a major contributor to problems in the humidity analysis, which have required ad hoc "fixes." The aim of the present reformulation is to rectify some of these shortcomings of the humidity analysis. We have adopted the approach of Dee and da Silva (2003) to recast the humidity analysis problem in terms of a transformed humidity variable for which short-range forecast errors exhibit near-normal distribution.

Normalized relative humidity. A large set of 3-h forecast differences, generated by an ensemble of data assimilations with randomly perturbed observations (Fisher and Andersson 2001; Fisher 2003), provided ample data for the study of short-range forecast error PDFs for humidity, and various transformed humidity variables. It was found that when error PDFs were stratified according to the value of the relative humidity they were easier to approximate with a Gaussian distribution. Based on these findings a normalized relative humidity variable was chosen as the new control variable for the revised humidity analysis (Hólm et al. 2002). The normalization factor is the standard deviation of the relative humidity error, stratified according to the relative humidity itself, with dependence on vertical level. The asymmetries in PDFs for conditions near zero humidity and near saturation are also accounted for (see Hólm et al. 2002 for a description) through a nonlinear transformation. The resulting error standard deviations in terms of either specific or relative humidity are thereby strongly dependent on the atmospheric state (Fig. 8). The figure shows that the resulting background error in terms of relative humidity is lower (orange shading) within the cold-air outbreak and within the saturated frontalzone region, and is higher (green) within the depression.

The transformed humidity variable has been implemented in the background constraint of 4DVAR (operationally in October 2003). It has been verified that the new humidity analysis in a broad sense gives the correct weight to all humidity sensitive radiance data (listed in Table 2) and also to SYNOP 2-m relativehumidity and radiosonde-specific humidity data. The radiosonde humidity observations are currently used below $300 \mathrm{hPa}$ only. Following the positive results of the Nash (2002) review of radiosonde humidity sensor performance, the use of several of the main operational radiosonde types above $300 \mathrm{hPa}$ was activated September 2004.

Tackling the spindown problem. The new humidity analysis formulation alone only slightly reduces the spindown in tropical precipitation. The spindown consists of fairly few, but strong, convective precipitation events at the start of the forecast $\left(20-50 \mathrm{~mm} \mathrm{~h}^{-1}\right.$ in T159 resolution experiments, not shown). To better understand the nature of the spindown, sensitivity experiments with minor changes to the humidity analysis were performed. In one such experiment the analysis increments were conditioned not to increase the rate of condensation in humid conditions (relative humidity $>80 \%$ ). It was found that this change, which reduces the zonal-mean boundary layer humidity by less than $1 \%$ (not shown), removes the spindown in tropical convective precipitation (Fig 9). The precipitation rate of the sensitivity experiment remains nearly constant in the Tropics during the first $24 \mathrm{~h}$ of forecasts, whereas in the reference experiment there is a rapid decrease 

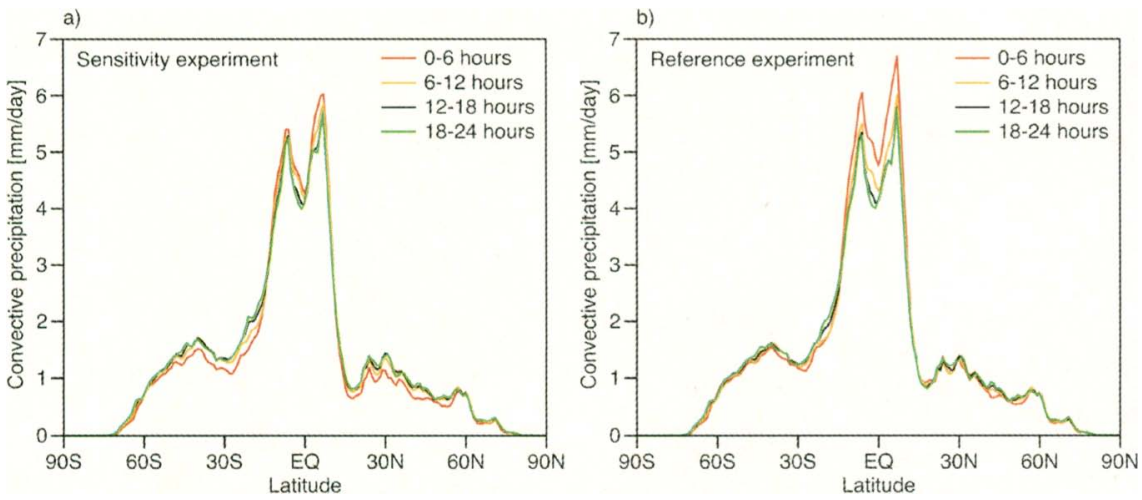

FIG. 9. 6-hourly forecast evolution of zonally averaged convective precipitation during the first $24 \mathrm{~h}$ (see legend). The average is over 18 forecasts starting $6 \mathrm{~h}$ apart over a 3-day period. In both panels, forecasts were started from analyses provided by the new humidity formulation. (b) The reference can be compared to (a) a sensitivity experiment in which the analysis increments were conditioned not to increase the rate-of-condensation in humid locations (relative humidity > $80 \%$ ). The sensitivity experiment successfully removes the spindown of tropical convective rainfall.

between the $0-6-$ and $6-12$-h periods. Humidity changes of this order (a few percent or less) are, as mentioned in section 2, below the accuracy of the current best humidity observations (Nash 2002). The best radiosondes can have 5\% relative humidity biases in the boundary layer. Further research on removing the spindown in the Tropics (and spinup in the extratropics) now concentrates on thermodynamical and dynamical balance constraints, since the observations on their own cannot be depended on to correctly constrain the humidity analysis.

CONCLUDING REMARKS. The current status of assimilation and modeling of the hydrological cycle at ECMWF has been reviewed. The emphasis has been on remote sensing of humidity from current and future satellite systems, in clear-sky, cloudy, and precipitation conditions, through direct radiance assimilation. The improved accuracy and the increasing availability of satellite information on Earth's hydrological cycle have brought this topic firmly into focus in recent years. This is reflected in the research plans of many NWP centers-for example, the British, French, Japanese, and Canadian meteorological services; the National Centers for Environmental Prediction (Washington, D.C.); Global Modeling and Assimilation Office (Washington, D.C.); and Forecast Systems Laboratory (Boulder, $\mathrm{CO}$ ), as detailed in the proceedings of a recent ECMWF/GEWEX workshop (ECMWF 2002). It is expected that this work will lead to forecast improvement through improved analysis in the precipitating regions of developing midlatitude weather systems and tropical cyclones.
Through comparison with in situ data, we have shown that the model's performance with respect to boundary layer humidity is often within the absolute accuracy of most current humidity observing systems (around 5\% relative humidity). From experience with reanalysis for the period 1957-2002 (the ERA-40 project) we have found that these small biases in model and data nevertheless lead to excessive tropical rain rates in analyses and shortrange forecast, that is, the "spindown" problem. The ERA-40 dataset is thus not in hydrological balance with a nonclosure of about $10 \%$, globally (see Table 1 and its discussion in the main text, and Betts et al. 2003a,b; Kållberg 2002; Troccoli and Kållberg 2004).

The operational status of satellite remote sensing of atmospheric humidity has been presented. Currently, assimilated data include radiances from the HIRS, AMSU-B, SSM/I, METEOSAT, GOES, and AIRS instruments, essentially in cloud-free conditions. A concerted effort is now being made to extend the radiance assimilation capability to cloudy and rainy conditions. Several approaches have been defined, with the ultimate goal being direct 4DVAR assimilation of cloudand rain-affected radiances. This will involve several new ingredients in the assimilation system, such as linearized moist physical processes, radiative transfer models (including scattering in clouds and precipitation), and enhancements to the 4DVAR system itself, as outlined in the "Cloud and Rain Assimilation" section. Multiple column retrievals (a 1DVAR framework) have shown very encouraging results in a case study of Typhoon Mitag and Tropical Cyclone Zoe.

Several of the above-mentioned aspects of the modeling and assimilation of the atmospheric hydrological cycle are likely to benefit from the recent development of a reformulated humidity analysis (previous section). The background term of the new formulation takes the wide-ranging variability of the humidity background errors better into account. This improves the interpretation of humidity data, and the inversion of information from radiances to four-dimensional distributions of temperature and humidity. Results show that the long-standing problem with spindown of tropical pre- 
cipitation can be reduced. Ways to reduce inconsistencies between humidity information from different observing systems, including an automatic bias correction procedure, require further investigation.

ACKNOWLEDGEMENTS. We owe many thanks to our ECMWF colleagues for discussions, suggestions, and contributions to the manuscript. We acknowledge the ground-breaking work of Jean-François Mahfouf and Virginie Marécal, which demonstrated that rain assimilation is indeed feasible. Anthony Hollingsworth and Martin Miller provided valuable comments on an earlier version of the manuscript. Stefan Hagemann and Klaus Arpe at the Max Planck Institute for Meteorology, Hamburg, provided diagnosis on the ERA-40 performance. Data for Fig. 4 were kindly provided by Chris Bretherton, University of Washington. Rob Hine skillfully improved the figures for publication.

\section{APPENDIX. Acronyms and abbreviations.}

1D/3D/4DVAR

AIRS

AMSU (A/B)

Aqua

ARM

CAPE

CMAP

COSMIC

CPC

CRU

DMSP

ECMWF

ELDAS

ENVISAT

EPIC

ERA-15/ERA-40

ESA

EUMETSAT one-/three-/four-dimensional variational data assimilation Atmospheric Infrared Sounder

Advanced Microwave Sounding Unit ( $A$ and $B$ )

Name of EOS-PM Earth Observing System satellite (NASA)

Atmospheric Radiation Measurement program

Convective available potential energy

CPC Merged Analysis of Precipitation

Joint U.S.-Taiwan radio occultation mission

Climate Prediction Center

Climate Research Unit

Defence Meteorological Satellite Program

European Centre for Medium-Range Weather Forecasts

European Land Data Assimiliation System

ESA's Environmental Monitoring Satellite

Eastern Pacific Investigation of Climate

ECMWF's 15- and 45-Year

Reanalysis projects

European Space Agency

European Organisation for the Exploitation of Meteorological Satellites
GOES

GMS

GPCC

GPCP

GPS

GRAS

HIRS

IASI

METEOSAT

METOP

MIPAS

MSG

NASA

NCEP

NOAA

NWP

PDF

RT

SEVIRI

SMOS

$\mathrm{SSM} / \mathrm{I}$

SYNOP

TCWV

TMI

TRMM

VTPR mental Satellites (NOAA)

Geostationary Meteorological Satellite

Global Precipitation Climatology Centre

Global Precipitation Climatology Project

Global Positioning System

The Global Navigation Satellite

System (GNSS) Receiver for

Atmospheric Sounding

High-Resolution Infrared Radiation Sounder

Infrared Atmospheric Sounding Interferometer

geostationary satellites

(EUMETSAT)

Meteorological Operational satellite (EUMETSAT)

Michelson Interferometer for Passive Atmospheric Sounding (ESA)

METEOSAT Second Generation

National Aeronautics and Space

Administration

National Centers for Environmental Prediction

National Oceanic and Atmospheric

Administration

Numerical Weather Prediction

Probability density function

radiative transfer

Spinning-Enhanced Visible and InfraRed Imager

Soil Moisture and Ocean Salinity

Mission (ESA)

Special Sensor Microwave Imager

data format for meteorological

surface stations

total column water vapor

TRMM Microwave Imager

Tropical Rainfall Measuring Mission (NASA)

Vertical Temperature Profile

Radiometer (NASA)
Geostationary Operational Environ-

\section{REFERENCES}

Alishouse, J. C., S. A. Snyder, J. Vongsathorn, and R. R. Ferraro, 1990: Determination of oceanic total precipitable water from the SSM/I. IEEE Trans. Geosci. Remote Sens., 28, 811-816. 
Andersson, E., J. Pailleux, J.-N. Thépaut, J. R. Eyre, A. P. McNally, G. A. Kelly, and P. Courtier, 1994: Use of cloud-cleared radiances in three/four-dimensional variational data assimilation. Quart. J. Roy. Meteor., 120, 627-653.

— tation of three-dimensional variational assimilation (3D-Var). III: Experimental results. Quart. J. Roy. Meteor. Soc., 124, 1831-1860.

Bauer, P., 2002: Microwave radiative transfer modelling in clouds and precipitation. Part I: Model description. NWP-SAF Doc. EC-TR-005, 27 pp. [Available from Met Office, Fitz Roy Road, Exeter EX1 3PB, United Kingdom.]

—, P. Amayenc, C. D. Kummerow, and E. A. Smith, 2001: Over-ocean rainfall retrieval from multisensor data of the Tropical Rainfall Measuring Mission. Part II: Algorithm implementation. J. Atmos. Oceanic Technol., 18, 1838-1855.

—, G. Kelly, and E. Andersson, 2002: SSM/I radiance assimilation at ECMWF. Proc. ECMWF/GEWEX Workshop on Humidity Analysis, Reading, United Kingdom, ECMWF and GEWEX, 167-175.

Baumgartner, A., and E. Reichel, 1975: The World Water Balance. Elsevier, 179 pp.

Beljaars, A. C. M., and P. Viterbo, 1998: The role of the boundary layer in a numerical weather prediction model. Clear and Cloudy Boundary Layers, A. A. M. Holtslag and P. Duynkerke, Eds., Royal Netherlands Academy of Arts and Sciences, 287-304.

,--1, M. J. Miller, and A. K. Betts, 1996: The anomalous rainfall over the United States during July 1993: Sensitivity to land surface parameterization and soil moisture anomalies. Mon. Wea. Rev., 124, 362-383.

Betts, A. K., J. H. Ball, M. Bosilovich, P. Viterbo, Y. Zhang, and W. B. Rossow, 2003a: Intercomparison of water and energy budgets for five Mississippi subbasins between ECMWF reanalysis (ERA-40) and NASA Data Assimilation Office fvGCM for 1990-1999. J. Geophys. Res., 108, 8618, doi:10.1029/ 2002JD003127.

$\longrightarrow,-$, and P. Viterbo, 2003b: Evaluation of the ERA-40 surface water budget and surface temperature for the Mackenzie River Basin. J. Hydrometeor., 4, 1194-1211.

Chevallier, F., and G. Kelly, 2002: Model clouds as seen from space: Comparison with geostationary imagery in the $11-\mu \mathrm{m}$ window channel. Mon. Wea. Rev., 130, 712-722.

—, and P. Bauer, 2003: Model rain and clouds over oceans: Comparison with SSM/I observations. Mon. Wea. Rev., 131, 1240-1255.
,-- , G. Kelly, C. Jakob, and T. McNally, 2001: Model clouds over oceans as seen from space: Comparison with HIRS/2 and MSU radiances. J. Climate, 14, 4216-4229.

- — - J.-F. Mahfouf, and J.-J. Morcrette, 2002: Variational retrieval of cloud profile from ATOVS observations. Quart. J. Roy. Meteor. Soc., 128, 25112525

—, P. Lopez, A. M. Tompkins, M. Janisková, and E. Moreau, 2004: The capability of 4D-Var systems to assimilate cloud-affected satellite infrared radiances. Quart. J. Roy. Meteor. Soc., 130, 917-932.

Courtier, P., J.-N. Thépaut, and A. Hollingsworth, 1994: A strategy for operational implementation of 4D-Var, using an incremental approach. Quart. J. Roy. Meteor. Soc., 120, 1367-1387.

Dee, D. P., and A. M. da Silva, 2003: The choice of variable for atmospheric moisture analysis. Mon. Wea. Rev., 131, 155-171.

Derber, J. C., and W.-S. Wu, 1998: The use of TOVS cloud-cleared radiances in the NCEP SSI analysis system. Mon. Wea. Rev., 126, 2287-2299.

Douville, H., P. Viterbo, J.-F. Mahfouf, and A. C. M. Beljaars, 2000: Evaluation of the optimum interpolation and nudging techniques for soil moisture analysis using FIFE data. Mon. Wea. Rev., 128, 17331756.

ECMWF, 2002: Proc. ECMWF/GEWEX Workshop on Humidity Analysis, Reading, United Kingdom, ECMWF and GEWEX, 234 pp.

Ellison, W. J., and Coauthors, 2003: A comparison of ocean emissivity models using the Advanced Microwave Sounding Unit, the Special Sensor Microwave Imager, the TRMM Microwave Imager, and airborne radiometer observations. J. Geophys. Res., 108, 4663, doi:10.1029/2002JD003213.

English, S. J., and T. J. Hewison, 1998: Fast generic millimeter-wave emissivity model. Proc. SPIE Conf. on Microwave Remote Sensing of the Atmosphere and Environment, Beijing, China, SPIE, 288-300.

—, R. J. Renshaw, P. C. Dibben, A. J. Smith, P. J. Rayer, C. Poulsen, F. W. Saunders, and J. R. Eyre, 2000: A comparison of the impact of TOVS and ATOVS satellite sounding data on the accuracy of numerical weather forecasts. Quart. J. Roy. Meteor. Soc., 126, 2911-2931.

Fillion, L., and J.-F. Mahfouf, 2003: Jacobians of an operational prognostic cloud scheme. Mon. Wea. Rev., 131, 2838-2856.

Fisher, M., 2003: Background error covariance modeling. Proc. ECMWF Seminar on Recent Developments in Data Assimilation for Atmosphere and Ocean, Reading, United Kingdom, ECMWF, 45-64. 
- , and E. Andersson, 2001: Developments in 4D-Var and Kalman filtering. ECMWF Tech. Memo. 347, $36 \mathrm{pp}$.

Garand, L., and Coauthors, 2001: Radiance and Jacobian intercomparison of radiative transfer models applied to HIRS and AMSU channels. J. Geophys. Res., 106, 24 017-24031.

Gérard, É. and R. Saunders, 1999: Four-dimensional variational assimilation of Special Sensor Microwave/Imager total column water vapour in the ECMWF model. Quart. J. Roy. Meteor. Soc., 125, 3077-3101.

Gregory, D., 1996: Sensitivity of general circulation model performance to convective parametrization. The Physics and Parameterization of Moist Atmospheric Convection, R. K. Smith, Ed., NATO ASI Series C, Vol. 505, Kluwer Academic, 463-482.

Harris, B. A., and G. Kelly, 2001: A satellite radiancebias correction scheme for data assimilation. Quart. J. Roy. Meteor. Soc., 127, 1453-1468.

Hólm, E., E. Andersson, A. Beljaars, P. Lopez, J.-F. Mahfouf, A. J. Simmons, and J.-N. Thépaut, 2002: Assimilation and modelling of the hydrological cycle: ECMWF's status and plans. ECMWF Tech. Memo 383, 55 pp.

Huffman, G. J., and Coauthors, 1997: The Global Precipitation Climatology Project (GPCP) combined precipitation dataset. Bull. Amer. Meteor. Soc., 78, 5-20.

Jakob, C., and S. A. Klein, 1999: The role of vertically varying cloud fraction in the parametrization of microphysical processes in the ECMWF model. Quart. J. Roy. Meteor. Soc., 125, 941-965.

Janisková, M., J.-F. Mahfouf, J.-J. Morcrette, and F. Chevallier, 2002a: Linearized radiation and cloud schemes in the ECMWF model: Development and evaluation. Quart. J. Roy. Meteor. Soc., 128, 15051527.

,$- \ldots$, and ——, 2002b: Preliminary studies on the variational assimilation of cloud-radiation observations. Quart. J. Roy. Meteor. Soc., 128, 2713-2736.

Kållberg, P., 2002: ERA-40 hydrological cycle. Proc. ECMWF/GEWEC Workshop on Humidity Analysis, Reading, United Kingdom, ECMWF and GEWEX, 101-105.

Köpken, C., G. Kelly, and J.-N. Thépaut, 2004: Assimilation of Meteosat radiance data within the 4D-Var system at ECMWF: Assimilation experiments and forecast impact. Quart. J. Roy. Meteor. Soc., 130, 2277-2292.

Macpherson, B., 2001: Operational experience with assimilation of rainfall data in the Met Office mesoscale model. Meteor. Atmos. Phys., 76, 3-8.
Mahfouf, J.-F., 1999: Influence of physical processes on the tangent-linear approximation. Tellus, 51A, 147166.

Marécal, V., and J.-F. Mahfouf, 2000: Variational retrieval of temperature and humidity profiles from TRMM precipitation data. Mon. Wea. Rev., 128, 3853-3866.

$\longrightarrow$, and —, 2002: Four-dimensional variational assimilation of total column water vapor in rainy areas. Mon. Wea. Rev., 130, 43-58.

- , and - 2003: Experiments on 4D-Var assimilation of rainfall data using an incremental formulation. Quart. J. Roy. Meteor. Soc., 129, 3137-3160.

—, É. Gérard, J.-F. Mahfouf, and P. Bauer, 2001: The comparative impact of the assimilation of SSM/I and TMI brightness temperatures in the ECMWF 4DVar system. Quart. J. Roy. Meteor. Soc., 127, 11231142.

—, J.-F. Mahfouf, and P. Bauer, 2002: Comparison of TMI rainfall estimates and their impact on 4DVar assimilation. Quart. J. Roy. Meteor. Soc., 128, 2737-2758.

Matricardi, M., 2003: RTIASI-4, a new version of the ECMWF fast radiative transfer model for the infrared atmospheric sounding interferometer. ECMWF Tech. Memo. 425, 63 pp.

_- and R. Saunders, 2001: A fast radiative transfer model for simulation of infrared atmospheric sounding interferometer radiances. Appl. Opt., 38, 5679-5691.

—, F. Chevallier, G. Kelly, and J.-N. Thépaut, 2004: An improved general fast radiative transfer model for the assimilation of radiance observations. Quart. J. Roy. Meteor. Soc., 130, 153-173.

McNally, A. P., 2002: A note on the occurrence of cloud in meteorologically sensitive areas and the implications for advanced infrared sounders. Quart. J. Roy. Meteor. Soc., 128, 2551-2556.

— humidity information from TOVS radiances. Quart. J. Roy. Meteor. Soc., 122, 1521-1544.

- , and P. D. Watts, 2003: A cloud detection algorithm for high-spectral-resolution infrared sounders. Quart. J. Roy. Meteor. Soc., 129, 3411-3423.

—, E. Andersson, G. A. Kelly, and R. W. Saunders, 1999: The use of raw TOVS/ATOVS radiances in the ECMWF 4D-Var assimilation system. ECMWF Newsletter, No. 83, ECMWF, Reading, United Kingdom, 2-7.

—, J. C. Derber, W. Wu, and B. B. Katz, 2000: The use of TOVS level-1b radiances in the NCEP SSI analysis system. Quart. J. Roy. Meteor. Soc., 126, 689724. 
Moreau, E., P. Bauer, and F. Chevallier, 2002: Microwave radiative transfer modeling in clouds and precipitation. Part II: Model evaluation. NWP-SAF Doc. EC-TR-006, 21 pp. [Available from Met Office, Fitz Roy Road, Exeter EX1 3PB, United Kingdom.]

—, P. Lopez, P. Bauer, A. M. Tompkins, M. Janisková, and F. Chevallier, 2004: Variational retrieval of temperature and humidity profiles using rain rates versus microwave brightness temperatures. Quart. J. Roy. Meteor. Soc., 130, 827-852.

Munro, R., C. Köpken, G. Kelly, J.-N. Thépaut, and R. Saunders, 2004: Assimilation of Meteosat radiance data within the 4D-Var system at ECMWF: Data quality monitoring, bias correction and singlecycle experiments. Quart. J. Roy. Meteor. Soc., 130, 2293-2313.

Nash, J., 2002: Review of test results on the accuracy of radiosonde relative humidity sensors. Proc. ECMWF/GEWEX Workshop on Humidity Analysis, Reading, United Kingdom, ECMWF and GEWEX, $117-123$.

New, M., M. Hulme, and P. Jones, 2000: Representing twentieth-century space-time climate variability. Part II: Development of 1901-96 monthly grids of terrestrial surface climate. J. Climate, 13, $2217-$ 2238.

Phalipou, L., 1993: A microwave radiative transfer model. ECMWF Tech. Memo. 190, 12 pp.

_ , 1996: Variational retrieval of humidity profile, wind speed and cloud liquid water path with the SSM/I: Potential for numerical weather prediction. Quart. J. Roy. Meteor. Soc., 122, 327-355.

Rabier, F., H. Järvinen, E. Klinker, J.-F. Mahfouf, and A. Simmons, 2000: The ECMWF operational implementation of four-dimensional variational assimilation. I: Experimental results with simplified physics. Quart. J. Roy. Meteor. Soc., 126, 1143-1170.

Rudolf, B., H. Hauschild, W. Rüth, and U. Schneider, 1996: Comparison of rain gauge analyses, satellitebased precipitation estimates and forecast model results. Adv. Space Res., 18, 53-62.

Saunders, R., M. Matricardi, and P. Brunel, 1999: An improved fast radiative transfer model for assimilation of satellite radiance observations. Quart. J. Roy. Meteor. Soc., 125, 1407-1425.

_, P. Brunel, F. Chevallier, G. Deblonde, S. English, M. Matricardi, and P. Rayer, 2002: RTTOV-7 science and validation report. Met Office Forecasting and Research Tech. Rep. 387, 51 pp.
Simmons, A. J., and A. Hollingsworth, 2002: Some aspects of the improvement in skill of numerical weather prediction. Quart. J. Roy. Meteor. Soc., 128, 647-677.

Sundqvist, H., E. Berge, and J. E. Kristjánsson, 1989: Condensation and cloud parameterization studies with a mesoscale numerical weather prediction model. Mon. Wea. Rev., 117, 1641-1657.

Tiedtke, M., 1993: Representation of clouds in largescale models. Mon. Wea. Rev., 121, 3040-3061.

—, W. A. Heckley, and J. Slingo, 1988: Tropical forecasting at ECMWF: The influence of physical parametrization on the mean structure of forecasts and analyses. Quart. J. Roy. Meteor. Soc., 114, 639664.

Tompkins, A. M., and M. Janisková, 2004: A cloud scheme for data assimilation: Description and initial tests. Quart. J. Roy. Meteor. Soc., 130, 2495-2517.

Treadon, R. E., 1997: Assimilation of satellite derived precipitation estimates with the NCEP GDAS. Ph.D. dissertation, The Florida State University, $348 \mathrm{pp}$.

Trémolet, Y., 2004: Diagnostics of linear and incremental approximations in 4D-Var. Quart. J. Roy. Meteor. Soc., 130, 2233-2251.

Troccoli, A., and P. Kållberg, 2004: Precipitation correction in the ERA-40 reanalysis. ERA-40 Project Report Series 13, 6 pp.

Tsuyuki, T., 1997: Variational data assimilation in the Tropics using precipitation data. Part III: Assimilation of SSM/I precipitation rates. Mon. Wea. Rev., 125, 1447-1464.

Van den Hurk, B. J. J. M., P. Viterbo, A. C. M. Beljaars, and A. K. Betts, 2000: Offline validation of the ERA40 surface scheme. ECMWF Tech. Memo 295, 42 pp.

Viterbo, P., and A. C. M. Beljaars, 1995: An improved land surface parameterization scheme in the ECMWF model and its validation. J. Climate, 8, 2716-2748.

- , and P. Courtier, 1995: The importance of soil water for medium-range weather forecasting. Implications for data assimilation. WMO Int. Workshop on Imbalances of Slowly Varying Components of Predictable Atmospheric Motions. Beijing, China, WMO, 121-130.

Xie, P., and P. Arkin, 1997: Global precipitation: A 17-year monthly analysis based on gauge observations, satellite estimates, and numerical model outputs. Bull. Amer. Meteor. Soc., 78, 2539-2558. 